\title{
(e) interface
}

comunicação, saúde, educação

https://www.interface.org.br

eISSN 1807-5762

\section{Resenhas}

\section{Das "pressões" cotidianas experienciadas pelos segmentos populares à "pressão alta" como adoecimento de longa duração}

From the daily "pressures" experienced by the popular segments to "high blood pressure" as a long-term illness

De las "presiones" cotidianas experimentadas por los segmentos populares a la "presión alta" como enfermedad de larga duración

\section{Reni Barsaglini(a)}

<barsaglinireni@gmail.com>

Lucas Pereira de Melo(b)

<lpmelo@usp.br>

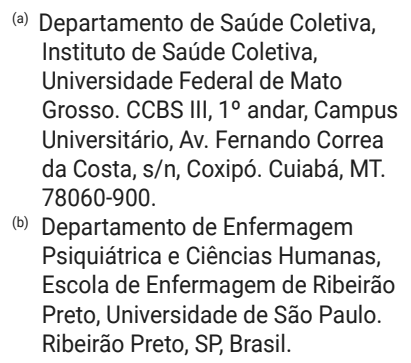

Em 2015, Ana Maria Canesqui - livre-docente em Ciências Sociais Aplicadas à Medicina, professora aposentada e colaboradora do Programa de Pós-Graduação em Saúde Coletiva da Universidade Estadual de Campinas - publicou pela Editora Fiocruz, como parte da série Antropologia e Saúde, o livro "Pressão alta no cotidiano: representações e experiências", resultante de pesquisa qualitativa conduzida pela autora em município do interior paulista. A obra condensa reflexóes sobre a temática dos adoecimentos de longa duração e, especificamente, sobre a pressão alta (hipertensão arterial sistêmica, no vocabulário biomédico). Nesse campo, a autora acumula vasta experiência e contribuiçốes teórico-metodológicas produzidas pelos pesquisadores do Grupo de Pesquisa Cultura, Saúde e

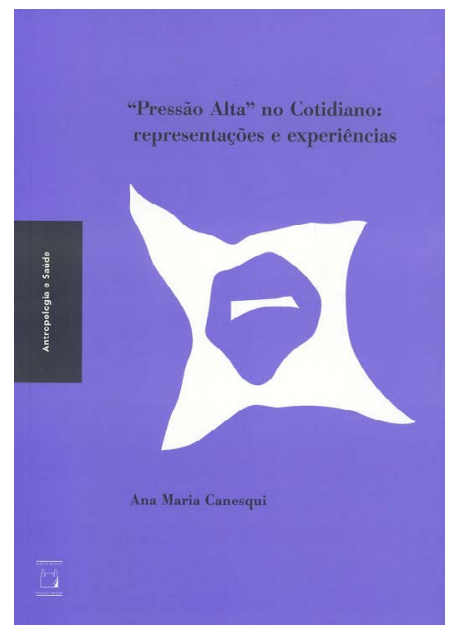

Canesqui AM. "Pressão alta” no cotidiano: representações e experiência. Rio de Janeiro: Fiocruz; 2015. 
Doença, que coordenou de 2005 a 2016. Além disso, sua produção científica na temática em tela envolve orientações de investigações na pós-graduação, projetos de pesquisas aprovados, participação em eventos científicos (principalmente a coordenação de grupo temático nas três últimas ediçóes do Congresso Brasileiro de Ciências Sociais e Humanas em Saúde, organizado pela Associação Brasileira de Saúde Coletiva) e a publicação de coletâneas pioneiras no Brasil, sobre o tema na perspectiva socioantropológica ${ }^{1,2}$. A solidez dessas produçóes soma-se à trajetória profissional da autora reiterando suas contribuiçốes para a constituição e para a consolidação do campo da Saúde Coletiva no Brasil, notadamente, na área de Ciências Sociais e Humanas em Saúde.

Dada a relevância que a pressão alta assume na agenda das políticas públicas de saúde, nas sociedades e associações científicas da área médica e, principalmente, pelo impacto produzido na vida das pessoas, o livro se destaca por agregar à literatura especializada uma análise inscrita no campo da Saúde Coletiva, em geral, e das Ciências Sociais e Humanas em Saúde, em particular. Nesse sentido, trata-se de uma obra de fôlego que aborda a pressão alta por meio de uma crítica revisão de literatura sobre os adoecimentos de longa duração. A revisão apresentada conflui para a proposta teórica e metodológica da autora de articular os conceitos de representação e experiência, estabelecendo, assim, o diálogo em um modelo aberto de investigação, cujo artesanato é meticulosamente descrito.

Se na análise de fenômenos socioculturais como os adoecimentos crônicos, a interpretação remete à ação do sujeito em meio à pluralidade de matrizes de significados e práticas (institucionalizadas ou não, dirá a autora) com enraizamento social e histórico, o substrato sociocultural de tais interpretaçóes se encontra em distintos níveis da realidade com fronteiras esmaecidas que se interpenetram. Diante desse entendimento, evoca-se a noção de integração que transversaliza a pesquisa do adoecimento, expressando-se nos diferentes níveis de análise (macrossocial, microssocial e biográfico contextualizado), nas dimensões simbólica (das representaçóes) e concreta (da experiência) da doença, bem como na relativização do peso das estruturas e da ação na construção e vivência da enfermidade ${ }^{3}$.

Tal articulação tem marcado as produções de integrantes do grupo de pesquisa referido acima, adotando, então, uma abordagem designada construtivista integradora que reconhece a singularidade do pensar e do agir nas situaçóes de adoecimento de longa duração, postas nas diversas trajetórias individuais e sociais. Tais situaçôes só ganham sentido se remetidas ao modo de vida, ou seja, reconhecem a realidade social constituída pelas práticas interacionais e interpretativas sem negligenciar a participação de elementos da estrutura social nessa constitutividade ${ }^{3}$.

Nessa perspectiva, a autora transita entre tais níveis com movimentos pendulares entre os termos representação e experiência diante do objeto que propóe analisar movimentos estes que, inclusive, expressam-se na apresentação dos dados que não é estanque, mas entremeada ao longo dos capítulos. Assim, sintetiza:

Tanto a experiência quanto as representaçóes se impregnam umas das outras, se transformam ou se acomodam em um processo de mútua interinfluência nas situações, nos contextos sociais e relacionais imediatos, no tempo e nos espaços sócio-históricos mais amplos, no decorrer do curso dos tipos das enfermidades 
de longa duração e segundo as singularidades biográficas, imersas nas condições materiais e imateriais da vida, nas relaçôes sociais, nas bagagens culturais, nos conhecimentos e hábitos acumulados, passíveis de ressignificação, mudança, permanência e continuidade ${ }^{4}$. (p. 18)

O livro está organizado em nove capítulos. O primeiro, intitulado "Enfermidades de longa duração: sociologia e antropologia anglo-saxônicas", apresenta uma revisão da literatura norte-americana e inglesa das áreas de Antropologia e Sociologia Médicas, na qual se enfatizam os autores, os objetos, os conceitos e as abordagens teóricometodológicas, realçando suas contribuiçôes, potencialidades e limitaçôes. Sem exaustividade, o capítulo fornece um panorama das publicações sobre os adoecimentos de longa duração, proporcionando riqueza de referências e ponto de partida para os iniciantes em pesquisas qualitativas sobre o tema. Cumpre destacar que, no Brasil, os estudos socioantropológicos sobre tais enfermidades ainda se centram em torno da produção científica daqueles países centrais, o que demonstra a necessidade de uma análise da literatura "sul-sul”, produzida principalmente na América Latina, cujas reflexôes teóricas e evidências simbólicas, certamente, trarão uma perspectiva mais próxima dos valores sociais e dos referenciais culturais que orientam e modelam as representações e experiências da população local.

A especificidade da literatura sobre a pressão alta encontra-se no segundo capítulo - "Hipertensão: interlocução com as Ciências Sociais e Humanas -, selecionandose artigos internacionais e nacionais das revistas de Saúde Pública e Saúde Coletiva, além de teses e dissertaçóes. Nesse capítulo, a invisibilidade conferida à produção nacional publicada em periódicos das Ciências Sociais e de outros países latinoamericanos, novamente, ganha relevo nas escolhas metodológicas da autora. Nesse sentido, questiona-se: qual público de leitores se pretende atrair com o livro? Quais os espaços acadêmicos que poderão recebê-lo e adotá-lo como bibliografia em seus cursos, diálogos e investigaçóes? Partindo do pressuposto de que, no Brasil, as Ciências Sociais e Humanas em Saúde têm se configurado como um campo de saberes e práticas intrinsecamente marcado por disputas epistemológicas, teórico-metodológicas e disciplinares ${ }^{5,6}$, não incluir periódicos das Ciências Sociais, apesar da literatura incipiente sobre o objeto estudado, suscita reflexôes e questionamentos.

Apesar disso, nas análises da autora, pode-se verificar, em ambos os contextos (nacional e internacional), a escassez de investigaçôes quando comparada às demais enfermidades de longa duração. Ainda nesse capítulo, são salientadas as lacunas e as críticas às polarizaçôes incorporadas pelas Ciências Sociais e Humanas em Saúde, como: "objetivismo/subjetivismo; estrutura/ação; pensamento/ação; material/ imaterial; coletivo/individual; ou entre razão/emoção (...)” ${ }^{4}$ (p. 73). A autora reitera a:

[...] necessidade de deslocar a ênfase das experiências subjetivas e singulares e da significação dada pelos entrevistados, articulando-as aos parâmetros socioculturais e aos contextos sociais e históricos mais amplos, sem desprezar as interferências do saber biomédico, da organização das políticas, dos serviços de saúde e as intervençôes profissionais.” ${ }^{4}$ (p. 73)

Nesse sentido, embute-se a discussão posta pelas Ciências Sociais e Humanas nas décadas finais do século XX de rompimento com os dualismos e as ilusórias 
dicotomias, recomendando a articulação das análises micro e macro e dos diálogos interdisciplinares ${ }^{7,8}$. Essa postura teórica e metodológica é explicitada no terceiro capítulo - "Percursos teóricos e metodológicos da construção da pesquisa". No trabalho de campo, foram entrevistados homens e mulheres idosos, pertencentes a um segmento da classe trabalhadora urbana de baixa renda, com diagnóstico médico de hipertensão arterial sistêmica há mais de um ano, atendidos em unidade de Saúde da Família de um município do interior paulista. Além desses, foram incluídos os profissionais de saúde do referido serviço.

Seguindo o percurso da autora, o leitor encontra no quarto capítulo "Hipertensão arterial sistêmica: saberes e política de saúde" - uma análise das características e dos fundamentos do modelo biomédico e epidemiológico, tanto na atenção médica individualizada/clínica quanto nas intervençóes sobre a população. Nessa perspectiva, são enfocados a organização e o funcionamento da Estratégia de Saúde da Família como central na operacionalização de políticas oficiais de controle e vigilância da pressão alta. Para tanto, Canesqui lança mão de informações advindas dos manuais técnicos, dos documentos oficiais e de profissionais da saúde que acompanham os interlocutores da pesquisa no contexto estudado. Assim, reitera-se o pressuposto teórico, apontado em outro texto de referência da pesquisadora ${ }^{1}$, de que as representaçóes e experiências com a enfermidade moldam-se, também, "por um conjunto de externalidades, referido às políticas sociais e de saúde, aos meios diagnósticos e terapêuticos e a outros condicionantes que interferem nas suas vidas" ${ }^{4}$ (p. 20). Com base na análise feita da obra, pode-se compreender que a opção textual de Canesqui em apresentar a perspectiva biomédica em primeiro plano, quando comparado aos capítulos posteriores, objetivou delinear o contexto macrossocial (ou estrutural) dos saberes e das práticas de saúde oficial com o qual os interlocutores mantêm relações e interações diversas. Talvez com isso, ainda que teça críticas e aponte as limitaçốes do modelo biomédico, a autora tenha, inclusive, assumido o risco de leituras que tendam a vislumbrar essa organização do texto como uma tentativa de superestimar ou hierarquizar saberes e práticas, em detrimento daqueles apresentados na sequência do livro.

Os cinco capítulos seguintes são dedicados à perspectiva dos adoecidos, entremeada pelos diversos aspectos integrantes da experiência com a enfermidade, sempre atravessada por representações, ações e avaliações. Já no capítulo cinco, intitulado "Representaçôes não eruditas da pressão alta”, a autora salienta as aproximaçôes e diferenças existentes entre saber erudito e não erudito, reconhecendo a mútua interação entre tais concepçóes e a não oposição absoluta entre elas. Tais representaçóes constroem-se a partir das tradiçóes e do conhecimento de senso comum produzidos pelas sensaçôes corporais que sintetizam "múltiplas ordens (físicas, simbólicas, do funcionamento do corpo e da condição da pessoa), associações com eventos, experiências e circunstâncias da vida, ameaçada pela manifestação súbita e inesperada da 'pressão alta"”‘ (p. 163). Além disso, aborda as sutis distinçôes classificatórias quanto à pressão alta, a ter problemas de pressão, a sofrer pressão ou à pressão. Emblemático que é, o sangue ganha centralidade nas explicações sobre o adoecimento que, também, é identificado com a natureza da pessoa e com a gravidade da enfermidade, associandose à metáfora da explosão, tanto física (veias, coração, cérebro) quanto das emoções, como expressóes morais dos sofrimentos e das circunstâncias sociais adversas, 
permeando as afliçóes e perturbaçóes da vida, do corpo e da pessoa, podendo atingir os nervos, gerando sentimentos (raiva, violência, agressões) nem sempre extravasados.

Nos capítulos seis e sete, as narrativas breves dos interlocutores confluem para a compreensão êmica das explicaçóes sobre a gênese da pressão alta e as circunstâncias nas quais descobriram que viviam com essa condição de longa duração (como "passar mal”, "dar infarto", "dar derrame” ou nos exames médicos). Os achados dessa pesquisa corroboram as evidências descritas na literatura utilizada pela autora sobre a etiologia da pressão alta nas narrativas de pessoas que vivem com a enfermidade. Nesse sentido, podem-se agrupar as principais explicações populares analisadas no livro da seguinte forma: (1) as "pressóes" sofridas pelos interlocutores no cotidiano, nas quais se imbricam categorias êmicas como "pessoa nervosa", "nervosismo", "sangue ferve" e "estressada", que interseccionam, na experiência com a enfermidade, marcadores sociais como gênero, raça, classe social e geração. Para os interlocutores, essas sensaçóes e traços da pessoa ("pessoa nervosa", por exemplo) são produzidos e fazem sentido no contexto cotidiano das classes trabalhadoras urbanas, marcado pelas tensões, papéis e obrigações que compõem as relaçôes familiares e com a vizinhança; (2) as formas de viver e de ser dos interlocutores no cotidiano, nas quais se destacam as formas de comer, as situaçóes de comensalidade, o uso de álcool e de tabaco e suas consequências que se materializam no corpo gordo. As narrativas dos interlocutores que possibilitaram tal interpretação são repletas de categorias êmicas como "exageros”, "extravagâncias”, "abusos”, "comer errado", "sal”, "açúcar", "comida forte”, "comida fraca”, "sangue grosso", etc. Esses e outros termos compóem uma rede semântica que integra julgamentos morais, representaçôes sobre estrutura e funcionamento do corpo, volição, o papel da comida na composição corporal e sua função como "combustível” para o trabalho. Além disso, essa rede semântica popular é atravessada por categorias médicas (como hábitos de vida) que possibilitam compreender o porquê se tem ou se vive com a "pressão alta"; e (3) a "pressão alta" como uma doença que vem de família como forma de interpretar as causas ou "predestinação inevitável” do adoecimento.

O oitavo capítulo - "Tratamentos médicos e não médicos no contexto da vida cotidiana" - analisa o lugar da enfermidade no cotidiano de cuidados dos interlocutores e os agenciamentos produzidos no sentido de integrar as prescriçóes dos profissionais da saúde e suas práticas, com vistas ao equacionamento dos números que marcam os parâmetros estabelecidos pela biomedicina e a política de saúde para o controle da "pressão alta”. Aqui são destacadas as maneiras próprias como cada sujeito mescla "tradiçóes, conhecimentos, gostos, escolhas e disposições habituais nas experiências cotidianas com a enfermidade”" (p. 220). Assim, as narrativas demonstraram como o gerenciamento da pressão alta envolve um conjunto de práticas de autocuidado (uso de medicamentos, restriçôes alimentares, exercícios físicos) orientadas por matrizes médicas e populares e fortemente dirigidas ao indivíduo como o responsável pelo sucesso do tratamento: "o melhor tratamento é a gente mesmo que tem que pôr na cabeça”, diz um entrevistado em relação ao tratamento. Por outro lado, a autora analisa como as recomendaçóes dos especialistas do sistema oficial de saúde não são adotadas plenamente e sem dificuldades pelas pessoas que vivem com a pressão alta. Nesse processo, chama-se a atenção para formas de tratamento engendradas em outros sistemas culturais de assistência à saúde, cujos saberes que orientam tais práticas estão associados às explicaçóes populares da causalidade da pressão alta. 
Os interlocutores destacaram (1) a importância do lazer e do entretenimento ([...] “assisto televisão"/“Adoro dar risada”); (2) as formas de enfrentamento das "pressões” cotidianas ("para mim não passar nervoso", "ser tranquila”, "não passar desgostos"); e (3) da fé e das práticas religiosas ("peço que o Espírito Santo esteja presente para ele [o médico] passar o remédio certo [...]"/"descobrir a causa certa").

Para finalizar, Canesqui traz no capítulo nove - "Oscar, Francisco, Doralice e Luciana: estudos de caso" - quatro casos nos quais apresenta uma análise das narrativas mais contextualmente e situada na biografia dos interlocutores. Tal estratégia metodológica tem sido frequente nas pesquisas desenvolvidas pelo grupo de pesquisa coordenado pela autora e marca uma possibilidade de situar no plano microssocial e biográfico os aspectos mais gerais que modelam a experiência e as representaçóes com a enfermidade - abordados em detalhe no capítulo quatro.

A obra em seu conjunto é uma leitura recomendada para acadêmicos, docentes e pesquisadores (das Ciências Sociais e Humanas, da Saúde e da interface entre elas) e para profissionais de saúde (assistência e gestão) por proporcionar uma perspectiva crítica e socioculturalmente mais sensível desse tipo de adoecimento, podendo beneficiar aqueles que o vivenciam (direta ou indiretamente) nos diferentes espaços da vida cotidiana, inclusive nos serviços de saúde.

Interessa, ainda, aos que iniciam no estudo do tema pela profusão de referências e detalhamento metodológico como, também, aos mais experientes, podendo ser uma fonte de inspirações intelectuais e de fomento às investigações dessa natureza sobre outros adoecimentos e condiçôes de longa duração que impóem cuidados cotidianos, guardando-se suas singularidades.

Ademais, com essa pesquisa, Ana Maria Canesqui consolida a abordagem Construtivista Integradora nos estudos socioantropológicos sobre adoecimentos de longa duração ao articular conceitual e metodologicamente as representaçóes sociais e a experiência com a enfermidade. Dessa forma, o livro alberga ao campo das Ciências Sociais e Humanas em Saúde uma importante contribuição, uma vez que pesquisas com essa orientação são emergentes, escassas e recentes no Brasil. Contudo, do ponto de vista das evidências simbólicas apresentadas, os resultados muito mais corroboram a literatura já publicada sobre o tema do que apontam para elementos novos e contextualmente situados sobre a experiência e as representaçôes dos interlocutores com a pressão alta. $\mathrm{O}$ peso dado à literatura e ao rigor teórico-metodológico deixou pouco espaço para o diálogo intersubjetivo do pesquisador (e de sua equipe) com o campo e seus agentes sociais. Tal diálogo é traço fundamental nas pesquisas sociais que, ao mesmo tempo, garantem rigor metodológico e validade dos resultados.

\section{Contribuições dos autores}

Ambos os autores participaram ativamente de todas as etapas de elaboração do artigo.

\section{Direitos autorais}

Este artigo está licenciado sob a Licença Internacional Creative Commons 4.0, tipo BY (https://creativecommons.org/licenses/by/4.0/deed.pt_BR).

$(\mathrm{cos}) \mathrm{Br}$ 


\section{Referências}

1. Canesqui AM, organizadora. Olhares socioantropológicos sobre os adoecidos crônicos. São Paulo: Hucitec, FAPESP; 2007.

2. Canesqui AM, organizadora. Adoecimentos e sofrimentos de longa duração. 2a ed. São Paulo: Hucitec; 2015.

3. Barsaglini RA. As representaçóes sociais e a experiência com o diabetes: um enfoque socioantropológico. Rio de Janeiro: Fiocruz; 2011.

4. Canesqui AM. "Pressão alta” no cotidiano: representações e experiência. Rio de Janeiro: Fiocruz; 2015.

5. Maksud I. Doenças/adoecimentos/sofrimentos de longa duração: diálogos das Ciências Sociais com a Saúde Coletiva. Polit Trab. 2015; 42:197-209.

6. Ianni AMZ, Spadacio C, Barboza R, Alves OSF, Viana SDL, Rocha AT. As ciências sociais e humanas em saúde na ABRASCO: a construção de um pensamento social em saúde. Cad Saude Publica. 2014; 30(11):2298-308.

7. Alves PC. A teoria sociológica contemporânea: da superdeterminação pela teoria à historicidade. Soc Estado. 2010; 25(1):15-31.

8. Corcuff P. As novas sociologias: construçôes da realidade social. Bauru: Edusc; 2001. 